\section{Abordaje de diagnóstico y terapéutico de la toxoplasmosis congénita}

Diagnostic and therapeutic approach to congenital toxoplasmosis

Jessica Jessenia Ollos Méndez

Médico general, Hospital Universitario,

jessiollos@hotmail.com,

https://orcid.org/0000-0003-4301-1298

Génesis Fernanda Ruiz Plúas

Médico general, Hospital de especialidades

Teodoro Maldonado Carbo,

genesisfer_ruiz93@hotmail.com,

https://orcid.org/0000-0002-3047-7454

Hugo Rolando Roca Castillo

Médico general, Hospital General de Manta

IESS, hugo.roca693@gmail.com,

https://orcid.org/0000-0001-5162-3265

Yamel Fernanda Olvera Morán

Médico general, Centro de salud Las naves de

Bolívar, jamel1994olvera@gmail.com,

https://orcid.org/0000-0003-2397-5225

Guayaquil - Ecuador

http://www.jah-journal.com/index.php/jah

Journal of American health

E-1

Esta obra está bajo una Licencia Creative Commons

Atribución-NoComercial-Compartirlgual 4.0 Internacional.

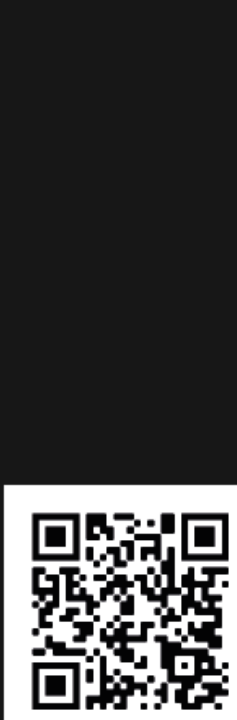

Scan this QR

code with your

smart phone or

mobile device to

read more papers

\section{RESUMEN}

La toxoplasmosis es una zoonosis que representa la segunda causa de infección congénita, se adquiere por primera vez cuando la infección por el parasito toxoplasma gondii infecta a una mujer embarazada, es importante detener las trasmisiones y el tratamiento oportuno para disminuir el riesgo de la trasmisión vertical, así como el desarrollo de manifestaciones clínicas en el feto. El diagnóstico de toxoplasmosis congénita puede no ser concluyente en muchos casos. A pesar de las diversas pruebas serológicas desarrolladas, la literatura sobre biomarcadores que pueden ayudar en el diagnóstico de toxoplasmosis congénita y aguda es limitada. El objetivo de este estudio fue analizar el perfil inmunorreactivo de las bandas proteicas de $T$. gondii con potencial de ser biomarcadores para el diagnóstico y pronóstico de la toxoplasmosis congénita y aguda. El objetivo de este estudio es actualizar los referentes teóricos sobre los métodos diagnósticos para determinar la infección de toxoplasmosis congénita. Se realizó una búsqueda sistemática de investigaciones recientes en bases de datos de Elsevier, Pubmed y Scopus de articulos publicados entre el 2016 al 2020, de idioma inglés y español. Se excluyeron artículos de reportes de casos. La finalidad de esta revisión es ofrecer a los médicos una información y orientación actualizada para optimizar su métodos diagnósticos y terapéuticos y error e la práctica de la atención primaria de salud, sobre todo, por las diferencias entre infección aguda y crónica de la toxoplasmosis congénita. 
PALABRAS CLAVE: toxoplasmosis congénita, epidemiología, serodiagnóstico, tratamiento

\section{ABSTRACT}

Toxoplasmosis is a zoonosis that represents the second cause of congenital infection, it is acquired for the first time when infection by the toxoplasma gondii parasite infects a pregnant woman, it is important to stop transmission and prompt treatment to reduce the risk of vertical transmission. , as well as the development of clinical manifestations in the fetus. The diagnosis of congenital toxoplasmosis may not be conclusive in many cases. Despite the various serological tests developed, the literature on biomarkers that can help in the diagnosis of congenital and acute toxoplasmosis is limited. The objective of this study was to analyze the immunoreactive profile of $\mathrm{T}$. gondii protein bands with the potential to be biomarkers for the diagnosis and prognosis of congenital and acute toxoplasmosis. The objective of this study is to update the theoretical references on diagnostic methods to determine congenital toxoplasmosis infection. A systematic search of recent research was carried out in Elsevier, Pubmed and Scopus databases of articles published between 2016 and 2020, in English and Spanish. Articles from case reports were excluded. The purpose of this review is to offer physicians updated information and guidance to optimize their diagnostic and therapeutic methods and errors in the practice of primary health care, especially due to the differences between acute and chronic infection of congenital toxoplasmosis.
KEY WORDS: congenital toxoplasmosis, epidemiology, serodiagnosis, treatment.

\section{INTRODUCCIÓN}

La toxoplasmosis es una infección producida por el parásito toxoplasma gondii, cuyo reservorio es el gato doméstico (felis catus), esta infección se transmite al humano por la diseminación de las heces del gato al medio ambiente, causando complicaciones graves en personas con el sistema inmunológico comprometido y en mujeres embarazadas ocasionando toxoplasmosis congénita. (1) Entonces, la transmisión congénita ocurre en la mayoría de los casos como resultado de la infección materna primaria durante la gestación. (2). Esta infección materna durante el embarazo puede tener consecuencias graves para el feto, que van desde aborto espontáneo, afectación del sistema nervioso central, retinocoroiditis o infección subclínica al nacer con riesgo de aparición tardía de enfermedades oculares.

Ante la ausencia frecuente de signos clínicos, el diagnóstico de la toxoplasmosis congénita se basa especialmente en pruebas de laboratorio efectuadas en laboratorios especializado que sin embargo son más comunes tamizarlas sobre todo por el impacto en salud publica en países de vías de desarrollo. El tratamiento de los recién nacidos infectados también puede reducir la gravedad de las consecuencias y la frecuencia de su aparición más adelante en la vida. (4)

La toxoplasmosis congénita (TC) es una de las formas de infección más importantes entre las enfermedades que afectan a los fetos. La infección es causada por 
Toxoplasma gondii y puede causar inviabilidad fetal o manifestaciones clínicas en cualquier etapa de la vida del niño. Además, presentan una incidencia global estimada de 1,5 casos por cada 1.000 nacidos vivos, caracterizándose como un problema de salud pública (5).

La detección precoz de la toxoplasmosis durante el cribado prenatal y/o neonatal junto con el inicio inmediato de un tratamiento adecuado conduce a un mejor pronóstico en los casos congénitos. El pronóstico se ha relacionado principalmente con el período de infección gestacional. En el primer trimestre, la infección puede provocar la muerte fetal (6). Los signos clínicos de la llamada tétrada de Sabin son comunes en el segundo trimestre $y$ en el tercer trimestre de gestación, donde generalmente los fetos están asintomáticos en el $80 \%$ de los casos, sin embargo, los signos clínicos pueden manifestarse en días, meses o años después del nacimiento (7).

El diagnóstico de laboratorio de la toxoplasmosis se basa principalmente en la detección de anti-T. gondii IgM e IgG, que determinan el estadio de la infección. Los anticuerpos IgM están presentes en la fase aguda de la infección y alcanzan niveles altos en un mes, sin embargo, debido a la vida media de los anticuerpos, estos se vuelven indetectables después de algunas semanas $(1,3,4)$. En algunos casos, anti-T. gondii IgM se puede detectar durante más de un año, lo que dificulta el diagnóstico, especialmente en casos con sospecha de infección en el primer trimestre del embarazo.

Las inmunoglobulinas IgM no atraviesan la barrera placentaria, por lo que son marcadores de infección congénita cuando se detectan en el suero de los recién nacidos. Sin embargo, se sabe que hasta el $55 \%$ de los recién nacidos infectados no tienen estos anticuerpos, o pueden presentarlos en niveles indetectables para la mayoría de las pruebas disponibles (5). Por otro lado, anti-T. gondii Los anticuerpos IgG disminuyen a un nivel residual medio después del tercer mes de infección, lo que determina la fase crónica de la enfermedad. Los anticuerpos IgG maternos están circulando en la sangre del niño, por lo que su presencia sugiere una infección congénita, ya que el título de esta clase de inmunoglobulinas permanece estable o ascendente hasta el primer año de vida del niño, lo que hace que el diagnóstico sea tardío $(6,7)$.

La técnica de inmunotransferencia se ha utilizado para confirmar el diagnóstico de toxoplasmosis congénita, sin embargo esta y las otras técnicas no determinan si la infección se debe a transmisión congénita o adquirida cuando se realiza después de los primeros meses de vida del niño (7). En este contexto, existe la necesidad de identificar biomarcadores que ayuden en el diagnóstico de casos no concluyentes de toxoplasmosis en gestante y en niños con infección congénita, que sean efectivos y brinden un tratamiento temprano para prevenir o minimizar los signos clínicos que pueden aparecer meses o meses. años después del nacimiento.

La finalidad de esta revisión es ofrecer a los médicos una información y orientación actualizada para optimizar su métodos diagnósticos y terapéuticos y reducir el error en la práctica de la atención primaria de salud, sobre todo, por las diferencias 
entre infección aguda y crónica de la toxoplasmosis congénita.

\section{MATERIALES Y MÉTODOS}

Se realizó una búsqueda bibliográfica en PubMed y Scielo, de los últimos 5 años previos a esta publicación. Se incluyeron estudios de revisión narrativa o sistemática sobre los métodos diagnósticos de la toxoplasmosis congénita escritos en idioma inglés o español. Se excluyeron los artículos sobre cartas a los editor y memorias de congresos. Se proyectó un total de 40 artículos, de los cuales se seleccionaron 34 investigaciones completas. De estos, 10 artículos no eran elegibles, ya que no contenían la evaluación diagnóstica de toxoplasmosis congénita y, por lo tanto, se excluyeron.

\section{RESULTADOS}

Toxoplasma gondii es un parásito intracelular obligado que se sabe que infecta a un tercio de la población mundial total de forma crónica, aunque es asintomático en pacientes inmunocompetentes. Sin embargo, en un paciente inmunodeprimido o en un feto infectado, puede causar efectos devastadores (8). El parásito puede atravesar la placenta de una mujer embarazada infectada y probablemente infectar al feto de forma congénita. La gravedad de la infección depende de la edad gestacional en la que se ha producido la infección. (8).

\section{Transmisión}

Cuando los ciclos de vida no se conocían por completo, la pregunta principal era cómo los humanos se infectaban con el gato. Sin embargo, en la actualidad, está bien establecido que existen tres rutas principales de transmisión de $T$. gondii: (a) ingerir alimentos y agua contaminados con heces de gato, que contienen ooquistes del parásito, (b) ingerir carne cruda o poco cocida que contiene quistes tisulares del parásito y (c) de forma congénita de la madre al feto a través de la placenta $(5,8)$. La infección transplacentaria ocurre cuando una madre no infectada adquiere la infección durante el embarazo. Hay otros modos de transmisión raros, como el trasplante de órganos, la transfusión de sangre y el laboratorio adquirido. En la India, esta infección es más común en poblaciones tribales $y$ socioeconómicamente atrasadas, particularmente en aquellos que trabajan descalzos y con las manos desnudas en los campos y consumen agua o vegetales contaminados (9). También se ha encontrado que es más frecuente en poblaciones donde la deficiencia de yodo es más pronunciada.

\section{Manifestaciones clínicas de la infección} congénita.

La gravedad y la probabilidad de infección dependen del trimestre del embarazo en el que la madre se infecta con T. gondii. La toxoplasmosis es más grave en los bebés cuyas madres se infectan durante el primer trimestre que en los del tercer trimestre. Transmisión de $T$. gondii desde las madres seropositivas antes de la concepción hasta sus bebés es poco común, pero se registran informes ocasionales de madres seropositivas que transmiten Toxoplasma a sus hijos (6). Aunque la mayoría de los niños con infección congénita son asintomáticos al nacer, pueden desarrollar algunos síntomas más adelante en la vida. La pérdida de la visión es la secuela más común (hasta el 95\%) en 
los niños con infección congénita. También puede ocurrir hidrocefalia, retinocoroiditis, coriorretinitis, calcificación intracerebral, retraso mental, pérdida de audición y, muy raramente, la muerte (10).

\section{Resultados obstétricos}

Mucho de lo que se sabe sobre el diagnóstico y el tratamiento de $T$. gondii durante el embarazo proviene de estudios en Austria y Francia, donde es obligatorio por ley realizar pruebas de detección de $T$. gondii en todas las mujeres embarazadas. Las mujeres se someten a pruebas de anticuerpos contra $T$. gondii en su primera visita a su ginecólogo $(8,9)$. Las mujeres seropositivas no se someten a más pruebas durante el embarazo en países donde no existen programas nacionales de detección; sin embargo, en países como Francia y Austria, todas las mujeres seropositivas también se someten a pruebas cada trimestre para determinar el aumento de los títulos de IgG. Las mujeres que seroconversión durante el embarazo son seguidos clínicamente y sus fetos se examinan para $T$. gondii infección por ultrasonidos y la amniocentesis y la presencia de $T$. gondii en líquido amniótico y sangre fetal (10).

Los hallazgos importantes de estos estudios son los siguientes (10):

- La infección de la madre antes del embarazo rara vez, o nunca, da como resultado el nacimiento de un niño infectado congénitamente.

- La mitad de las mujeres que contraen la infección por $T$. gondii durante el embarazo no transmiten el parásito al feto.

- T. gondii se transmite con mayor frecuencia durante la última parte de la gestación, pero la enfermedad es más grave si la infección se adquiere durante el primer y segundo trimestre.

- La detección de T. gondii en el líquido amniótico es posible con la reacción en cadena de la polimerasa (PCR)

- Excepto en raras ocasiones, $T$. gondii no causa abortos ni esterilidad en las mujeres

\section{Abordaje diagnóstico}

Las pruebas de toxoplasmosis congénita en el feto deben realizarse cuando la madre haya confirmado la infección o cuando existan hallazgos ecográficos sugestivos como calcificaciones intracraneales $O$ dilatación ventricular cerebral. La PCR positiva para el ADN de $T$. gondii en el líquido amniótico confirma el diagnóstico en el feto (10).

Debe sospecharse toxoplasmosis congénita en el recién nacido en las siguientes situaciones (11):

- Infección materna primaria por $T$. gondii durante el embarazo

- Madres inmunodeprimidas con infección previa por T. gondii

- Recién nacidos con características clínicas indicativas de toxoplasmosis congénita

- Recién nacidos con cribado neonatal positivo para toxoplasma

El diagnóstico resulta de una combinación de hallazgos clínicos y de laboratorio.

\section{Pruebas serológicas}

Los anticuerpos específicos de Toxoplasma (IgG, IgM e IgA) requieren pruebas en todos los casos de sospecha de infección. La vida media de los anticuerpos 
IgM e IgA contra el Toxoplasma es de 5 y 10 días. Cuando existe la preocupación de falsos positivos debido a la contaminación materna de la sangre fetal durante el trabajo de parto, se deben repetir las pruebas serológicas 10 días después del nacimiento. EI ADN de $T$. gondii por PCR también es posible en LCR, orina o sangre periférica (11).

Los criterios de diagnóstico para la infección confirmada son uno de los siguientes (11):

- Presencia de anticuerpos IgM y/o IgA específicos de Toxoplasma 10 días después del nacimiento

- Título de IgG persistente o en aumento sin tratamiento en bebés de 1 año de edad o más

- PCR positiva para ADN de $T$. gondii o anticuerpos IgM $\quad$ o $\quad$ Ig A de Toxoplasma positivos en el LCR

La IgG positiva es indicativa de una infección materna previa o actual. En presencia de otras características sugestivas, pero anticuerpos IgM e IgA negativos, la prueba de toxoplasma IgG requiere repetición cada 4 a 6 semanas hasta la desaparición completa. Los anticuerpos IgM e IgA negativos no excluyen la infección (12). Si la madre se ve afectada más adelante en su embarazo, hay un retraso en la producción de anticuerpos en el recién nacido. Cuando se sospecha una infección, los anticuerpos deben repetirse cada 2 a 4 semanas hasta al menos los 3 meses de edad. La interpretación de las pruebas serológicas es compleja. Por lo tanto, deben enviarse a laboratorios de referencia regional para su confirmación (13).
El diagnóstico de toxoplasmosis aguda a menudo se pasa por alto porque la infección aguda no se presenta con ningún síntoma o signo patognomónico. Puede presentarse con características muy leves similares a la gripe con 0 sin linfadenopatía. En muy raras ocasiones, se puede notar un brote de erupción central en un examen cuidadoso $(12,13)$. Por estas razones, la mayoría de los pacientes ignoran la infección aguda. Por lo tanto, una fuerte sospecha clínica es la clave para las investigaciones de laboratorio, que juegan un papel crucial. El diagnóstico de laboratorio se puede realizar mediante serología, aislamiento de cultivos (en modelos animales o líneas celulares) o métodos moleculares como la PCR.

Se ha demostrado que el cribado gestacional es rentable, ahorra morbilidad, y salva vidas. (9). Hallazgos proporcionan evidencia adicional de que el tratamiento antiparasitario, si se administra durante el embarazo, puede contribuir a mejores resultados clínicos. (15). El diagnóstico de infección fetal se realiza mediante reacción en cadena de la polimerasa (PCR) en líquido amniótico obtenido a partir de la semana 18 de gestación. Si esta prueba resulta positiva, debe iniciarse tratamiento a la embarazada con pirimetamina, sulfadiazina y ácido folínico. (11) (12).

\section{Serodiagnóstico}

La detección de anticuerpos específicos de Toxoplasma es el método de diagnóstico principal para determinar la infección por Toxoplasma. Las pruebas de detección de anticuerpos contra el toxoplasma se realizan mediante numerosas pruebas serológicas, y la mayoría de ellas están disponibles comercialmente para detectar anticuerpos específicos de $T$. gondii IgG e 
IgM (16). El Sabin-Feldman DT, la prueba de anticuerpos fluorescentes indirectos (IFAT), IHAT, la prueba de aglutinación de látex (LAT), DAT y el ensayo de inmunoabsorción ligado a enzimas (ELISA) son algunas de las pruebas que se utilizan para detectar anticuerpos contra $T$. gondii. Aunque el DT es el más específico, rara vez se usa ahora porque usa $T$. gondii virulento vivo. El IFAT es casi tan sensible como el DT, pero requiere un microscopio fluorescente (18).

Los IFAT, LAT, DAT y ELISA se utilizan con más frecuencia. En 2003 se publicó un algoritmo para el inmunodiagnóstico de la toxoplasmosis en individuos $>1$ año de edad con la ayuda de un diagrama de flujo. El ensayo de inmunofluorescencia y el inmunoensayo enzimático (EIA) Las pruebas de anticuerpos IgG e IgM son las más utilizadas en la actualidad. Las personas deben someterse a pruebas inicialmente para detectar la presencia de anticuerpos IgG específicos de Toxoplasma para determinar su estado inmunológico (18).

La presencia de anticuerpos IgG solo significa exposición porque los seres humanos asintomáticos pueden desarrollar un $T$. gondii muy alto (> 100.000) los títulos de anticuerpos y los títulos pueden permanecer elevados durante varios años o incluso durante toda la vida si se encuentran exposiciones repetidas. Aunque un aumento de 8 veces en los títulos de anticuerpos, tomados con 2 semanas de diferencia, es indicativo de una infección reciente, esto rara vez se logra en la práctica porque cuando los pacientes son atendidos en la clínica, el título de anticuerpos por lo general ha alcanzado su punto máximo $(14,15)$. En comparación con los anticuerpos IgG, los anticuerpos IgM son de corta duración y aparecen antes que los anticuerpos IgG.

Si se necesita un conocimiento más preciso del momento de la infección, entonces una persona con IgG positiva debe realizarse una prueba de IgM mediante un procedimiento con reacciones inespecíficas mínimas, como EIA de captura de IgM (16). Una prueba de IgM negativa esencialmente excluye una infección reciente, pero una prueba de IgM positiva es difícil de interpretar porque los anticuerpos IgM específicos de Toxoplasma pueden detectarse mediante EIA hasta 18 meses después de la infección aguda adquirida (19).

\section{Prueba de avidez IgG}

La avidez de IgG (capacidad de unión del anticuerpo con el antígeno) es una prueba muy útil. La avidez de IgG se puede probar mediante ELISA o el Vitek ImmunoDiagnostic Assay System (VIDAS, BioMerieux SA, Francia). Este último está más estandarizado y tiene sus propios controles y estándares de sistema. En una mujer embarazada cuya muestra se toma en el segundo trimestre en lugar de idealmente en el primer trimestre, y se encuentra IgG positiva, pero IgM negativa, es más recomendable realizar una prueba de avidez de IgG (19). Las pruebas de IgG de alta avidez indican que adquirió la infección hace más de 4 meses. Sin embargo, la baja avidez no es una prueba de confirmación de una infección reciente.

Antes de iniciar el tratamiento del paciente para la toxoplasmosis aguda, todos los positivos de IgM deben ser verificados por un laboratorio de referencia 
con experiencia en toxoplasmosis. En cualquier caso, el microbiólogo clínico debe asesorar al paciente de forma patente, una práctica que no existe en el subcontinente indio, ya que la mayoría de los microbiólogos clínicos no interactúan directamente con los pacientes.

\section{Serodiagnóstico en el recién nacido}

El diagnóstico de toxoplasmosis congénita en un recién nacido presenta muchas dificultades debido a la transferencia de anticuerpos IgG materiales al feto, la baja sensibilidad de las pruebas serológicas y la falta de disponibilidad y costo de los kits de detección de $\lg A$ específicos de $T$. gondii $(2,8)$. Los bebés recién nacidos y los bebés con sospecha de toxoplasmosis congénita deben someterse a pruebas mediante EIA de captura de IgM e IgA. La detección de anticuerpos IgA específicos de Toxoplasma es más sensible que la detección de IgM en bebés con infección congénita (10). Teniendo en cuenta el alto costo de un programa de detección de toxoplasmosis congénita durante el embarazo, un programa para detectar anticuerpos IgM contra $T$. gondii en la sangre del cordón, junto con la detección de otras infecciones congénitas, podría ser más rentable que la detección de toxoplasmosis sola (20).

\section{Tratamiento}

La toxoplasmosis se puede tratar con rovamicina (espiramicina), un fármaco que se comercializa en forma de tabletas que contienen cada una $3 \mathrm{MUI}(1 \mathrm{~g})$ de sal de espiramicina. La espiramicina es un antibiótico macrólido que se une de forma irreversible a la subunidad ribosómica de los años 50 inhibiendo la síntesis de proteínas microbianas (21). Es uno de los pocos antimicrobianos capaces de penetrar intracelular, incluidos los macrófagos, eliminando así los patógenos intracelulares en etapas tanto activas como portadoras de la enfermedad.

El fármaco se administra por vía oral. El ácido gástrico parece tener un efecto mínimo, pero la coadministración con alimentos reduce significativamente la biodisponibilidad y retrasa el tiempo hasta la concentración máxima. A diferencia de los altos niveles que se encuentran en la mayoría de los tejidos y líquidos corporales, no penetra en el líquido cefalorraquídeo. La transferencia placentaria es deficiente $y$ solo el $9-16 \%$ que se encuentra en la concentración sanguínea materna aparece en el líquido amniótico (21).

La droga se elimina del cuerpo lentamente, la mayoría inactivada en los tejidos. Dado que es un macrólido, está contraindicado en personas que se sabe que tienen hipersensibilidad a este grupo de medicamentos. De lo contrario, el medicamento se tolera bien y las reacciones adversas graves son extremadamente raras. No existen contraindicaciones específicas para su uso durante la lactancia. En mujeres embarazadas, se administran de $6 \mathrm{MUI}$ a 9 MUI (2-3 comprimidos) al día en 2 o 3 dosis divididas durante 3 semanas (22).

Este curso de 3 semanas debe repetirse después de un intervalo de 2 semanas hasta el parto. En mujeres embarazadas con infección confirmada por Toxoplasma, se ha administrado espiramicina oral $1 \mathrm{~g} 3$ veces al día para prevenir la transmisión al feto. En estas mujeres, el fármaco debe iniciarse lo antes posible después del diagnóstico materno comprobado o sospechado y continuarse durante todo el 
embarazo. Está indicado el seguimiento de la presencia de infección fetal $(20,22)$. Los recién nacidos y lactantes con toxoplasmosis congénita confirmada y los varones adultos con toxoplasmosis adquirida deben tratarse con pirimetamina más sulfadiazina.

Otros fármacos que muestran una tasa de curación variable son la azitromicina, la atovacuona y la dapsona. La espiramicina no tiene ningún papel en la toxoplasmosis posnatal. En pacientes con SIDA, la claritromicina da mejores resultados. Sin embargo, debido a la baja eficacia de todos los fármacos actualmente disponibles y los efectos secundarios asociados con la combinación de fármacos sulfa + pirimetamina, se ha acelerado la búsqueda de nuevos compuestos (22).

\section{DISCUSIÓN}

Se ha demostrado que el tratamiento eficaz contra el Toxoplasma, cuando se instituye ya en el útero durante el período gestacional, reduce significativamente la transmisión de madre a hijo y mejora los resultados clínicos $(1,5,9)$. Por lo tanto, es imperativo que las pruebas de laboratorio empleadas para el diagnóstico de TC sean sensibles, específicas y exhiban valores predictivos altos para identificar rápidamente a los fetos y recién nacidos que probablemente se beneficien significativamente de las intervenciones de tratamiento. Aquí, revisamos las pruebas serológicas que están actualmente disponibles para los médicos para el diagnóstico de CT (10). Se mencionan métodos adicionales, como PCR, tinciones histológicas, aislamiento del parásito en ratones y estudios de imágenes cerebrales, y otras anomalías generales de laboratorio asociadas con la enfermedad, pero no se revisan en detalle ya que están más allá del alcance de esta revisión. Además, la relevancia de los antecedentes maternos (edad gestacional en la que la madre estaba infectada y si la madre recibió tratamiento antitoxoplasma o no) se incorpora a un algoritmo de diagnóstico.

El diagnóstico del neonato se realiza en líquido amniótico en la 18 semana de gestación mediante $\mathrm{PCR}$ reacción de cadena de polimerasa, una de los limitantes es que el IGA y PCR pueden dar falsos negativos por esto es importante determinar el ascenso de los Ac- IGG o persistencia de estos durante el seguimiento incluso durante el primer año de vida del niño, siendo esta una indicación de inicio de tratamiento. El $80 \%$ son asintomáticos, pero desarrolla manifestaciones visuales y neurológica durante su infancia $(12,18,20)$.

Los anticuerpos IGG se trasmite de la madre al hijo, se determina en la 1 ra y 2 da semana postinfección, e se incrementa hasta la 6ta y 8va. Indica exposición al parasito. Pues permanece positiva durante toda la vida. La técnica de western blot en el suero del niño permite diferenciar la fuente si es de madre o hijo. La IgM positiviza a la 1 semana postinfección, y alcanza su pico al mes, y desciende a los 20 3 meses. Sirve para orientar la posibilidad de infección reciente. En el RN es determinante; IgA e IgE es informativa no diagnostica en el RN igual que la IgM (23).

A pesar de estos muchos avances en nuestra comprensión de la prevención y el tratamiento de la toxoplasmosis congénita, quedan importantes áreas de estudio: necesitamos mejores medicamentos, estrategias bien 
definidas para el cribado de mujeres embarazadas, mejora de la seguridad alimentaria y mejores pruebas de diagnóstico. (13) una de ellas es el diagnóstico prenatal que se realiza actualmente mediante análisis de PCR en líquido amniótico. (22). Las limitaciones de las técnicas serológicas utilizadas para el diagnóstico de la toxoplasmosis hacen necesario validar nuevas metodologías que permitan aumentar su sensibilidad y especificidad, con el fin de obtener una prueba que brinde resultados muy confiables y un diagnóstico correcto. $(23,24)$

\section{CONCLUSIONES}

El T. gondii es un parásito coccidiano y más prevalente en animales de sangre caliente, incluidos los seres humanos. Si la infección se adquiere durante el embarazo, puede provocar toxoplasmosis congénita, que puede provocar anomalías congénitas de leves a graves e incluso pérdida fetal. Sin embargo, la infección adquirida una vez no tiene ningún papel en las pérdidas de embarazos múltiples. La espiramicina (rovamicina) es el fármaco de elección que previene la transmisión transplacentaria del parásito. Sin embargo, si el parásito ya ha atravesado la placenta, la espiramicina no puede revertir el daño causado al feto. Para el tratamiento de la toxoplasmosis posnatal (p. Ej., Mujeres o varones no embarazadas), la combinación de sulfadiazina más pirimetamina es la mejor opción. Como ocurre con cualquier otra infección, es mejor prevenir que tratarla. Los mejores métodos para prevenir la infección son una higiene personal adecuada.

Afortunadamente es poco frecuente, sin embargo, sus consecuencias graves en niños son motivo de interés y preocupación en el área de salud pública y pediatría. El diagnóstico definitivo dependerá de la seroconversión de la IGG durante el embarazo o el aumento de 3 o más de los títulos de IgG entre dos extracciones separadas de 3 y 4 semanas una IGM positiva en el primer trimestre sospecha de infección reciente pero no indica seguridad, una correcta interpretación de estas pruebas disminuye tratamientos innecesarios estrés materno ansiedad e incluso interrupciones de la gestación.

El diagnóstico de laboratorio de la toxoplasmosis congénita se beneficia de varios principios y métodos. Las investigaciones futuras deberían abordar el costo y la viabilidad de la detección de anticuerpos, ADN y parásitos vivos en diferentes plataformas y compartimentos corporales.

\section{REFERENCIAS}

1. Jiménez et al. Cumplimiento de la guía de práctica de la toxoplasmosis congénita en Colobia en los últimos veinte años. Universidad de Córdoba. 2020 julio.

2. López MG. Frecuencia de toxoplasmosis congénita en niños de la Ciudad de México detectados por tamiz neonatal. Universidad Nacional Autónoma de México. 2014.

3. Martine Wallon FP. Toxoplasmosis congénita: una súplica por una enfermedad desatendida. Pathogens. 2018 febrero; 7(1).

4. Bobić B. Prevención y mitigación de la toxoplasmosis congénita. Costos y beneficios económicos en diversos 
entornos. Food and Waterborne Parasitology. 2019 septiembre; 16.

5. Mandelbrot L. Toxoplasmosis congénita: ¿cuál es la evidencia de la quimioprofilaxis para prevenir la infección fetal? Prenatal Diagnosis. 2020 mayo 26; 40(13): p. 1693-1702.

6. Strangaf A. Carga de toxoplasmosis congénita en Brasil: revisión sistemática y metanálisis. Acta Tropica. Vol.1(2):23-9. 2020 noviembre.

7. Sánchez et al. Toxoplasmosis y embarazo. Rev Cubana Obstet Ginecol. 2012.

8. Khan K. Taxoplasmosis congénito: Una revisión de las manifestaciones neurológicas y oculares. Parasitology International. 2018 diciembre; 67(6): p. 715-721.

9. Bissati et al. Iniciativa global para la toxoplasmosis congénita: un análisis clínico observacional e internacional comparativo. Emergency Microbes \& Infections. 2018 septiembre 27;: p. 114.

10. Tudor Rares Olariu CPJTKOJGM. Toxoplasmosis congénita en los Estados Unidos: hallazgos clínicos y serológicos en bebés nacidos de madres tratadas durante el embarazo. Parasite. 2018 marzo 06.

11. Baquero-Artigao et al. Guía de la Sociedad Española de Infectología Pediátrica para el diagnóstico y tratamiento de la toxoplasmosis congénita. Asociación Española de Pediatría. 2013 agosto; 79(2).

12. Dardé M. Toxoplasma y toxoplasmosis. EMC. Pediatría. 2018 junio;: p. 1-13.
13. MacAuley J. Congenital Toxoplasmosis. Journal of the Pediatric Infectius Diseases Society. 2014 septiembre.

14. Francois Jieffer MW. Capítulo 112 Toxoplasmosis congénita. Handbook of Clinical Neurology. 2013; 112: p. 1099-1011.

15. Singh S. Toxoplasmosis congénita: características clínicas, resultados, tratamiento y prevención. Trop Parasitol. 2016 julio-diciembre;: p. 113-122.

16. Santiago Beltrán-Flores JFAMLC. Toxoplasmosis congénita. Boletín médico del Hospital Infantil de México. 2014 noviembre-diciembre.

17. toxoplasmosis Ty. M.-L. Dardé. F. Peyron. EMC - Pediatría. 2013 marzo; 48(1).

18. Orozco KMYAYBP. Evaluación de antígenos recombinantes SAG1 y GRA7 en el diagnóstico de la toxoplasmosis congénita, en el departamento de Sucre. Universidad de Sucre. 2015.

19. Carral et al. Toxoplasmosis congénita: Diagnóstico serológico, RPC, aislamiento y caracterización molecular de Toxoplasma gondii. Revista chilena de infectología. 2018.

20. Arguello et al. Toxoplasmosis congénita diagnóstico y tratamiento. RECIMUNDO: Revista Científica de la Investigación y el Conocimiento. 2020;: p. 118-127.

21. Pomares C. Diagnosis de laboratorio del toxoplasmosis congénita. Journal of Clinical Microbiology. 2016.

22. Bollani L. Congenital toxoplasmosis. Early Human Development. 2013 octubre; 89(4). 
23. Alvarado-Socarras J. No todo es zika:

Toxoplasmosis congénita. ¿Aún

prevalente en Colombia? Rev Perú

Med Exp Salud Pública. 2017;: p. 332-

336.

24. Luciana Robinoa L. Colestasis neonatal por toxoplasmosis congénita. Arch Argent Pediatr. 2013;: p. e105-e108. 